\title{
CORRECTIONS
}

\section{Publisher Correction: Topological phases in acoustic and mechanical systems}

\section{Guancong Ma(D), Meng Xiao (D) and C. T. Chan}

Nature Reviews Physics (2019) https://www.nature.com/articles/s42254-019-0030-x

Published online 1 March 2019

This article has been corrected to add a missing image credit to the caption of Fig. 4 . The credit line of Fig. 4 now reads "Panel $\mathbf{d}$ is adapted from ref.78, CC-BY-4.0 and an image courtesy of Dr Miniaci, Swiss Federal Laboratories for Materials Science and Technology.”

https://doi.org/10.1038/s42254-019-0060-4 I Published online 15 April 2019 